New data belp to determine whether differences in philanthropic practices are due to race and ethnicity themselves or to a variety of factors that are correlated with these labels.

\title{
Religious and secular giving, by race and ethnicity
}

\section{Richard Steinberg, Mark Wilhelm}

PATTERNS OF GIVING and volunteering by different racial and ethnic groups have been subjected to increasingly sophisticated scrutiny of late. Surveys (for example, Hodgkinson and Weitzman, 1996) suggest that African American and Hispanic families are less likely to make charitable donations or volunteer and make smaller average donations (or volunteer fewer hours) than white and Anglo families. However, the interpretation of these results is far from clear for at least four reasons. First, differences in giving and volunteering may result from differences in income, education, and other factors rather than race or ethnicity. Second, differences may reflect differing selective response rates. Those who are less generous may not admit this to the interviewer, and the willingness to answer questions may differ across racial or ethnic groups. Third, differences may reflect patterns of charitable solicitation or volunteer recruitment rather than differences in underlying generosity. Finally, differences in reported giving and volunteering may reflect 
differing understandings of the survey questions rather than differences in real behavior.

Our study contributes to the first two aspects of interpretation. We employ a large and rich data source, the Center on Philanthropy Panel Study (COPPS), to determine whether racial and ethnic differences remain after the confounding effects of other factors are removed. COPPS data are of extremely high quality, with exceptional response rates to questions about giving (Wilhelm, 2003). COPPS began in 2001 as a supplement attached to the Panel Study on Income Dynamics (PSID), an ongoing survey repeated annually from 1968 to 1999 and every two years since then. The PSID has followed the same individuals since its inception, together with their progeny and anyone else who became part of their (or their children's) families. For the 2001 wave analyzed here, there are 7,406 PSID family units, almost all of whom responded to the COPPS questions. From the rest of the PSID, we have an extensive and carefully constructed set of control variables with which to conduct our analysis.

\section{What do other studies find?}

Studies that control for confounding factors come to diverse conclusions about whether apparent differences in giving or volunteering are due to race or ethnicity. Carson (1989) finds that blacks are substantially less likely to make charitable donations than whites at every level of income, his only control variable. Conley (2000) notes the distinction between income (the rate at which financial resources are arriving) and wealth (the total financial resources available at a point in time), criticizing Carson for his failure to include the latter. Using PSID data from 1994, he finds that blacks have substantially lower wealth at all levels of income than whites. Furthermore, he finds that other control variables commonly used in studies of racial differences in giving do not serve as adequate proxies for the missing data on wealth. 
He speculates that wealth controls would eliminate the remaining difference in giving but bemoans the lack of appropriate data, recommending that "a new survey be conducted that combines aspects of the PSID and the Joint Center-Gallup Survey of Philanthropic Activity" (p. 538). That is precisely what COPPS does, and we report the results here.

O'Neill and Roberts (2000) report on a survey of about thirtysix hundred California residents interviewed in 1998-1999. They find that white, African American, and Asian/Pacific Islanders give and volunteer at comparable rates and levels, whereas Latinos have lower participation rates. These differences disappear when results are adjusted for differences in income, education, and immigration status.

Eschholz and Van Slyke (2002) find a mixed pattern for blacks in the metropolitan Atlanta area. They find that blacks are significantly less likely to make a donation after controlling for age, education, marital status, employment, children in the household, religious service attendance, political party, gender, and attitude toward government. Race has no effect on the amount given in general, but among women, blacks gave significantly less than whites. Finally, there are no significant differences in the likelihoods of black and white volunteering. Notably, they could not control for income because 47 percent of respondents refused to answer the question. In a related paper, Van Slyke and Eschholz (2002) find that blacks volunteer more than whites, with the difference significant for black women but not men. Interestingly, they find that men in the category Other Race volunteer significantly less than either black or white men.

Yen (2002) employs data from the 1995 Consumer Expenditure Survey. He too finds that race effects disappear from a system of equations that explain charity, religious, and other organizational giving once one controls for income, age, and education. Musick, Wilson, and Bynum (2000) cite six previous studies that find that racial differences in volunteering disappear once controls for socioeconomic status are included, two that find that whites 
volunteer more than blacks even after controls, one that finds white women are more likely to volunteer than black women but volunteer the same number of hours when they do, and four that find blacks volunteering more than whites. They attribute the differences to varying definitions of volunteering, methods of analysis, and subject populations and call for more study with better data sets. Their own study finds the gap reduced but still present after introducing a variety of control variables, with blacks volunteering less than whites.

Mesch, Rooney, Chin, and Steinberg (2004) analyze the giving and volunteering of 885 Indiana respondents. They find that race does not affect the probability of making a donation, the size of the gift, the probability of volunteering, or the amount of volunteering after controlling for gender, marital status, income, age, education, and survey methodology. A follow-up study (Rooney, Mesch, Chin, and Steinberg, forthcoming) obtained similar results for the probability of donating and the size of the gift using a national sample of forty-two hundred respondents.

In summary, existing literature is not voluminous and obtains mixed results on whether racial and ethnic differences are real. Existing studies are hampered by potentially serious omittedvariable bias, particularly that caused by the omission of family wealth. Existing studies also suffer, to an unknown degree, from biases due to nonresponse to survey questions on giving and volunteering.

\section{Monetary gifts, by race of family head}

Our main findings report on donations by African American families (those whose head is African American regardless of the race of other members of the family unit) versus donations by other families (whom we refer to as white in this chapter). These results indicate that if we remove the confounding influences of other variables, there is no significant difference between the giving of black and white families. If anything, black families are slightly more gen- 
erous ( $\$ 1,363$ per family versus $\$ 1,325)$. Blacks are noticeably more generous in religious giving ( $\$ 924$ versus $\$ 814$ ) and a bit less generous in secular giving ( $\$ 439$ versus $\$ 510$ ), although these differences are not statistically significant.

Our method for computing this is a bit nonstandard and needs further explanation. First, we use multivariate methods to estimate an equation that can be used to predict the giving of anyone in the sample from knowledge of their income, education, wealth, race, ethnicity, and many other factors. (We also included controls for generation, sex, marital status, number and age of children, health status, region, city size, and religious denomination. For further details, a longer version of this chapter is available from us.) Using this equation, we obtain the predicted giving of every black family in the sample. For white families, we predict how much they would give if their income, education, wealth, and other variables remained the same, but instead of being headed by a white, they were headed by a black. Combining these two sets of predictions, we compute average donations if every family in the sample was black. Then we repeat the exercise, this time leaving the white families alone and predicting the giving of black families if they were to "turn white." The difference between these two numbers is our estimate of the impact of race.

\section{Monetary gifts, by ethnicity of family head}

The analysis for ethnicity reveals that apparent differences between Hispanics and others are due to the other factors rather than ethnicity. We predict that if everyone in the sample were Hispanic but retained current levels of income and other factors, that average gifts per family would be $\$ 1,195$ versus $\$ 1,336$ for non-Hispanic families and $\$ 1,251$ for families whose ethnicity is not known to us. These differences are quite noticeable, but not large enough to provide assurance that they represent something real rather than the luck of the draw in constructing our sample; in technical terms, the differences are not statistically significant. 


\section{Volunteering, by race of family head}

Unlike donations, which are reported at the family level, volunteering is reported at the individual level for family heads and family wives/“wives." Under PSID nomenclature, adult women or men are regarded as family heads if no spouse or long-term cohabitant of the opposite sex is present, regardless of their marital status. If a spouse or long-term cohabitant of the opposite sex from the head is present, this person is regarded as the wife or "wife" regardless of gender and marital status. The term Wife/"Wife" is awkward, and we shall henceforth refer to this person as the spouse. Thus, we report our findings separately for (1) heads where no spouse is present, (2) heads where a spouse is present, (3) spouses, and (4) families where both a head and spouse are present.

Data on volunteering by heads when no spouse is present strongly suggest that black single heads are less likely to volunteer, but despite this fact, the average number of hours volunteered (including nonvolunteers in the computation of the average) is about the same as that for whites. Our results suggest 15 percent of black single heads volunteer a predicted average of thirty-nine hours versus 26 percent of white single heads volunteering a predicted average of thirty-eight hours. This is due to the fact that blacks who do volunteer give many more hours on average than white volunteers do. We note that there are only thirty-three volunteers who are single black heads in our sample, so this average is strongly affected by a few outliers who may or may not be representative of the broader population. We then report adjusted estimates that take account of the fact that our black volunteers differ in many ways other than race from white volunteers. Our adjustments here are far more tentative than those we provide for donations due to the press of time, and although we find that predicted average volunteering by single black heads is about an hour more than that for single white heads, this difference is not statistically significant.

The pattern is different for black heads with spouses present. Blacks are less likely to volunteer but give more hours when they 
do volunteer, so that there is no apparent difference in the predicted average hours, including nonvolunteers.

The pattern for spouses is very similar to the pattern for heads in families where both are present. Spouses of black heads are substantially less likely to volunteer (18 percent versus 34 percent) and volunteer substantially fewer hours, regardless of the exclusion of nonvolunteers. There is a bit more precision about our preliminary estimates of predicted average volunteering: twenty-four hours for blacks versus forty-five for whites, statistically significant at the 11 percent level.

Finally, we present our data for family volunteering (the sum of head and spouse volunteering). Once again, blacks appear to volunteer less in every way this is measured. Our preliminary estimates of predicted average volunteering are the clearest yet, showing fortysix hours for black families versus eighty hours for white families, a difference that is statistically significant at the 10 percent level. However, his figures for predicted volunteering are preliminary.

\section{Conclusion}

In this chapter, we advance the literature on whether apparent differences in the giving and volunteering of black versus white, or Hispanic versus other families, are real. We employ new data, COPPS, that allow us to determine whether the differences are due to race and ethnicity themselves or a variety of factors that are correlated with these labels. Otherwise identical black and white families vary in many ways not captured by other available studies, especially in their stock of available assets - their net wealth. We control for family wealth. Our data have much lower levels of nonresponse than other available data, so we also gather evidence on whether apparent differences are due to differential response rates to surveys.

We find that differences in giving are indeed an artifact of confounding variables. We estimate that if everyone's race or ethnicity changed but their income, wealth, education, and many other 
factors remained the same, the average family donations would not change very much; we cannot reject the hypothesis that race and ethnicity have no effect whatsoever on total family giving. There are some hints that otherwise identical blacks give a larger share of their donations to religious causes, but this difference is not statistically significant. The picture is more complicated if our estimates for volunteering are taken at face value, but these estimates are quite preliminary. Single-headed black families are predicted to volunteer about the same amount as single-headed white families, but both black family heads and their spouses volunteer substantially less than their white counterparts in families where both are present, so that total volunteering is significantly lower in black families.

To place these results in context, let us recall the other problems suffered by studies of this type. We are unable to deal with the third and fourth problems cited in the introduction: differential solicitation and volunteer recruitment and differential understanding of survey questions. Wilson and Musick $(1997,1998)$ and Musick, Wilson, and Bynum (2000) find that patterns of volunteer recruitment matter; Bryant, Jeon-Slaughter, Kang, and Tax (2003) extend these results to solicitation of money. The latter find, however, that even controlling for solicitation status, blacks (and, less significantly, Hispanics) are less likely to volunteer and donate.

Differences in reported giving and volunteering may also reflect differing understandings of the survey questions rather than differences in real behavior. For example, Smith, Shue, Vest, and Villarreal (1999) find that some ethnic groups describe their philanthropic activities as "sharing' and 'helping"" (p. 6) rather than "charity." These groups may not recall or report the full extent of their queried activities in response to memory prompts and questions that speak of donations to nonprofit organizations. Some aspects are explored in a series of papers that look at differences in reported giving and volunteering by type of questionnaire (Rooney, Steinberg, and Schervish, 2001; Steinberg, Rooney, and Chin, 2002; Rooney, Steinberg, and Schervish, 2004), and whether the type of questionnaire matters in the same way to respondents of different races or 
genders (Mesch, Rooney, Chin, and Steinberg, 2004; Rooney, Mesch, Chin, and Steinberg, forthcoming).

If the differences are real, there are still questions about whether they are meaningful. Carson (1991) points out that if the causes typically supported by blacks (and, by extension, Hispanics) have different needs, there is no reason to expect black supporters to have the same generosity exhibited by supporters of other causes. In addition, generosity is expressed in many ways other than formal giving and volunteering through nonprofit organizations, including immigrant remittances, help to family and friends, gifts to strangers, and even donation of blood and body parts. Do differences found in, say, volunteering reflect differences in the level of generosity, or merely its composition? A bit of evidence on this comes from Carson (1989), who finds that blacks are more likely to give money, food or clothing, or perform some other service for the homeless or for a needy friend at all surveyed levels of income, and for a needy neighbor, a needy relative, or a needy individual at some levels of income.

\section{References}

Bryant, W. K., Jeon-Slaughter, H., Kang, H., and Tax, A. "Participation in Philanthropic Activities: Donating Money and Time." Fournal of Consumer Policy, 2003, 26, 42-73.

Carson, E. D. "The Evolution of Black Philanthropy: Patterns of Giving and Voluntarism.” In R. Magat (ed.), Philantbropic Giving: Studies in Varieties and Goals. New York: Oxford University Press, 1989.

Carson, E. D. "Contemporary Trends in Black Philanthropy: Challenging the Myths.” In D. F. Burlingame and L. J. Hulse (eds.), Taking Fund Raising Seriously: Advancing the Profession and Practice of Raising Money. San Francisco: Jossey-Bass, 1991.

Conley, D. "The Racial Wealth Gap: Origins and Implications for Philanthropy in the African American Community." Nonprofit and Voluntary Sector Quarterly, 2000, 29, 530-540.

Eschholz, S. L., and Van Slyke, D. M. "New Evidence About Women and Philanthropy: Findings from Metro Atlanta." Mimeographed, Georgia State University, 2002.

Hodgkinson, V. A., and Weitzman, M. Giving and Volunteering in the United States: Findings from a National Survey. Washington, D.C.: INDEPENDENT SECTOR, 1996. 
Mesch, D. J., Rooney, P. M., Chin, W., and Steinberg, K. S. "The Effects of Race, Gender, and Measurement on Giving and Volunteering: Indiana as a Test Case." Working paper, Center on Philanthropy at Indiana University, 2004.

Musick, M. A., Wilson, J., and Bynum, W. B. "Race and Formal Volunteering: The Differential Effects of Call and Religion.” Social Forces, 2000, 78, 1539-1571.

O’Neill, M., and Roberts, W. Giving and Volunteering in California. San Francisco: University of San Francisco, Institute for Nonprofit Organization Management, 2000.

Rooney, P. M., Mesch, D. J., Chin, W., and Steinberg, K. S. "The Effects of Race, Gender, and Survey Methodologies on Giving in the U.S." Economics Letters, forthcoming.

Rooney, P. M., Steinberg, K. S., and Schervish, P. G. "A Methodological Comparison of Giving Surveys: Indiana as a Test Case." Nonprofit and Voluntary Sector Quarterly, 2001, 30, 551-568.

Rooney, P. M., Steinberg, K. S., and Schervish, P. G. "Methodology Is Destiny." Nonprofit and Voluntary Sector Quarterly, 2004, 33, 628-654.

Smith, B., Shue, S., Vest, J. L., and Villarreal, J. Philanthropy in Communities of Color. Bloomington: Indiana University Press, 1999.

Steinberg, K. S., Rooney, P. M., and Chin, W. "Measurement of Volunteering: A Methodological Study Using Indiana as a Test Case.” Nonprofit and Voluntary Sector Quarterly, 2002, 31, 484-501.

Van Slyke, D. M., and Eschholz, S. L. "Are Women More Generous than Men? Gender Differences in Motivations for Charitable Giving." Paper presented at the ARNOVA Annual Conference, Montreal, Quebec, Canada, 2002.

Wilhelm, M. "The Distribution of Giving in Six Surveys." Mimeographed, Indiana University-Purdue University Indianapolis, 2003.

Wilson, J., and Musick, M. A. "Who Cares? Toward an Integrated Theory of Volunteer Work." American Sociological Review, 1997, 62, 694-713.

Wilson, J., and Musick, M. A. "The Contribution of Social Resources to Volunteering." Social Science Quarterly, 1998, 79, 799-814.

Yen, S. T. "An Econometric Analysis of Household Donations in the USA." Applied Economics Letters, 2002, 9, 837-841.

RICHARD STEINBERG is professor of economics, philanthropic studies, and public affairs, Indiana University-Purdue University Indianapolis, and associate director of the Center on Philanthropy Panel Study.

MARK WILHELM is associate professor of economics and philanthropic studies, Indiana University-Purdue University Indianapolis, and director of the Center on Philanthropy Panel Study. 